http://jmscr.igmpublication.org/home/

ISSN (e)-2347-176x ISSN (p) 2455-0450

crossref DOI: https://dx.doi.org/10.18535/jmscr/v7i10.152

Journal Of Medical Science And Clinical Research

IGM Publication

An official Publication of IGM Publication

\title{
A Hospital based study on surgical management of Acute Intestinal Obstruction
}

\author{
Authors \\ Dr Arun Katari ${ }^{1}$, Dr CH.Maruthi ${ }^{2 *}$ \\ ${ }^{1}$ Associate Professor, Department of General Surgery, Prathima Institute of Medical Sciences, Naganoor, \\ Karimnagar \\ ${ }^{2}$ Associate Professor, Department of General Surgery, Prathima Institute of Medical Sciences, Naganoor, \\ Karimnagar \\ *Corresponding Author \\ Dr CH. Maruthi
}

Flat number 217, Royal Pavilion Apartments, Beside RBI officers quarters, Ameerpet, Hyderabad-500016

Telangana State, India

Abstract
Acute intestinal obstruction is a medical emergency because of its potential for bowel ischemia leading
to perforation and peritonitis. Early recognition and appropriate treatments are thus required for better
outcomes. We in the current study tried to evaluate the epidemiology and outcome of surgical
management of acute intestinal obstruction in our tertiary care teaching hospital.
Methods: This prospective cross sectional study was done in the Department of General Surgery,
Prathima Institute of Medical Sciences, Nagunoor, Karimnagar. A total of n=50 cases were identified
and treated during the period of the study. The complete medical history and thorough clinical
examination of each patient were done. A detailed recording of all symptoms such as colicky abdominal
pain, nausea, vomiting, abdominal distention, absence of bowel movement and inability to pass flatus
were recorded. After the examination the patients were subjected to radiological investigations which
included plain upright abdominal radiograph, ultrasonography was done in patients who were not
suitable for CT examination.
Results: The most common presenting symptom in the patients was abdominal pain in 100\% of the
patients followed by constipation in $n=84 \%$ of patients. The most common signs were Tachycardia in
$n=78 \%$, abdominal tenderness in $n=64 \%$, and rigidity in $n=48 \%$. Hernioplasty was performed in
$n=20(40 \%)$ of the patients and hernioplasty with adhesiolysis in $n=7(14 \%)$ of the patients. Untwisting
the volvulus was done in $n=3(6 \%)$, Adhesiolysis was performed in $n=6(12 \%)$ of patients. Resection and
anastomosis were performed in $n=10$ (20\%) of the patients. Ileotransverse anastomosis was done in
$n=4(8 \%)$ of the patients.
Conclusion: Acute intestinal obstruction is a life-threatening surgical emergency and requires prompt
diagnosis and effective therapy. The most common etiological factor for acute intestinal obstruction in
our study was hernia followed by adhesions. Best outcomes are for patients with early diagnosis and
skillful management within a reasonable time frame. Poor prognosis is generally related to older
patients and late presentation to the hospital.
Keywords: Acute Intestinal obstruction, surgical management, Hospital based study.




\section{Introduction}

Acute intestinal obstruction is one of the most commonly encountered surgical emergencies. Small bowel obstruction accounts for $80 \%$ of all intestinal obstruction ${ }^{[1]}$. The etiology of obstruction varies from one region to the other region. Intestinal obstructions are differentiated into the small bowel and large bowel obstructions. Some of the common causes of intestinal obstructions are adhesions, neoplasms, and herniation $^{[2]}$. Bowels obstructions are subdivided into functional which are caused by bowel wall or splanchnic nerve dysfunction and it may be mechanical due to mechanical barriers. The mechanical small bowel obstructions are classified into luminal, mural or extra-mural mechanical barriers. Mechanical obstructions are generally seen in the Asian subcontinent. The mechanical obstructions although are generally managed by conservative treatments however, it may also necessitate emergency surgical intervention. Some of the classical signs of intestinal obstruction include colicky abdominal pain, nausea and vomiting, abdominal distension, and cessation of flatus and bowel movements. Diagnosis of intestinal obstruction is based on the initial evaluation of clinical signs and symptoms, radiography, CBP. The radiography can accurately diagnose intestinal obstruction in approximately $60 \%$ of cases $^{[3]}$. The important concern in intestinal obstructions is because of strangulation, causing bowel ischemia, necrosis and perforation may be involved and it is generally difficult to distinguish simple obstruction from strangulation ${ }^{[4]}$. The decision regarding the most appropriate treatment for obstruction is generally associated with rapid diagnostic and therapeutic management. It is generally not required to perform an emergency surgical procedure. The routine management depends to a certain extent on the causes of obstruction and also includes corrections of fluid and electrolyte balance, management of pain and patient monitoring. Intestinal obstruction in older patients is often challenging due to less reliable symptoms, and clinical presentations are likely to vary widely ${ }^{[5]}$. Mortality due to intestinal obstruction is found to be decreasing due to a better understanding of pathophysiology, improvement of diagnostic techniques. However, mortality may be more in elderly individuals who seek late treatment and those having associated pre-existing diseases such as diabetes mellitus or cardiac disease or respiratory diseases ${ }^{[6]}$. Early diagnosis and skillful operative management intensive postoperative care will have excellent outcomes. With this background, we in the present study tried to evaluate the outcome of surgical management of acute intestinal obstructions in our hospital.

\section{Material and Methods}

This prospective cross-sectional study was done in the Department of General Surgery, Prathima Institute of Medical Sciences, Nagunoor, Karimnagar. Institutional Ethical committee permission was obtained for the study. Written consent was obtained from all the participants of the study. The inclusion criteria were: All adult patients of both sexes with clinical history, radiological examination and hematological parameters suggestive of acute intestinal obstruction. Those patients who were managed by the surgical intervention were included. Those managed conservatively were excluded. Only patients willing to participate voluntarily were selected in the study. Exclusion criteria: pediatric patients with acute intestinal obstruction, the patients with severe comorbidities which are likely to affect the outcome, those not willing to participate in the study. A total of $n=50$ cases were identified and treated during the period of the study. The complete medical history and thorough clinical examination of each patient were done. A detailed recording of all symptoms such as colicky abdominal pain, nausea, vomiting, abdominal distention, absence of bowel movement and inability to pass flatus were recorded. After the examination the patients were subjected to radiological investigations which 
included plain upright abdominal radiograph, ultrasonography was done in patients who were not suitable to CT examination due to severe illness or those patients who require avoidance of radiation exposure. Laboratory investigations were performed that included complete blood picture, BT and CT, CRP, Hematocrit, Kidney function tests, Liver function tests. Surgery was done in patients to prevent ischemia, necrosis, perforation and peritonitis and in cases where obstructions were not managed adequately with conservative therapy. Surgical management was done with resuscitation with IV fluids (Ringer Lactate and NS). Antibiotic prophylaxis was started. All the vital parameters like BP, Pulse rate, urine output, abdominal girth, bowel sounds, tenderness and guarding were noted. Surgeries were performed in various patients based on diagnosis and operative needs. Hernioplasty was performed in $\mathrm{n}=20(40 \%)$ of the patients and hernioplasty with adhesiolysis in $n=7(14 \%)$ of the patients. Untwisting the volvulus was done in $\mathrm{n}=3(6 \%)$, Adhesiolysis was performed in $\mathrm{n}=6(12 \%)$ of patients. Resection and anastomosis were performed in $\mathrm{n}=10(20 \%)$ of the patients. Ileotransverse anastomosis was done in $n=4(8 \%)$ of the patients. Histopathological examination of the tissue specimen was done wherever required. The postoperative period was monitored carefully and nasogastric tube aspiration, intravenous fluids, and antibiotics were continued and complication was recorded and managed adequately. Postdischarge follow up was done up till 6 months. All the obtained data were recorded in the MS Excel spreadsheet and analyzed by appropriate statistical analysis.

\section{Results}

During the duration of the study, we found $n=50$ patients diagnosed with acute intestinal obstruction out of which $n=35$ were male and $\mathrm{n}=15$ were females. The most common age group was $61-70$ years with $24 \%$ of cases least common patients were seen in 20-30 years and 51-60 years with $12 \%$ of patients each. The mean age group of male patients in the study 45.5 years and female was 49.5 years shown in table 1 .

Table 1: Age distribution of patients with acute intestinal obstruction

\begin{tabular}{|c|c|c|c|c|}
\hline Age group & Male & Female & Total & Percentage \\
\hline $\mathbf{2 0}-\mathbf{3 0}$ & 4 & 2 & 06 & 12 \\
\hline $\mathbf{3 1}-\mathbf{4 0}$ & 6 & 2 & 08 & 16 \\
\hline $\mathbf{4 1}-\mathbf{5 0}$ & 7 & 3 & 10 & 20 \\
\hline $\mathbf{5 1}-\mathbf{6 0}$ & 5 & 1 & 06 & 12 \\
\hline $\mathbf{6 1}-\mathbf{7 0}$ & 8 & 4 & 12 & 24 \\
\hline$>\mathbf{7 0}$ & 5 & 3 & 08 & 16 \\
\hline Total & 35 & 15 & 50 & 100 \\
\hline
\end{tabular}

The socio-economic conditions of the patients revealed $n=29$ were from a poor background and $\mathrm{n}=21$ were from an average background. Based on the food habits out of $n=50$ patients $n=5$ were vegetarians and rest were non-vegetarians. The most common presenting symptom in the patients was abdominal pain in $100 \%$ of the patients followed by constipation in $n=84 \%$ of patients. The most common signs were Tachycardia in $\mathrm{n}=78 \%$, abdominal tenderness in $\mathrm{n}=64 \%$, and rigidity in $\mathrm{n}=48 \%$ the other details are shown in table 2.

Table 2: Showing signs and symptoms of the patients in the study

\begin{tabular}{|l|c|c|}
\hline \multicolumn{2}{|l|}{$\begin{array}{c}\text { Number of } \\
\text { patients (n=50) }\end{array}$} & Percentage \\
\hline SYMPTOMS & 50 & 100 \\
\hline Abdominal Pain & 12 & 24 \\
\hline Vomiting & 34 & 68 \\
\hline Abdominal Distension & 30 & 60 \\
\hline $\begin{array}{l}\text { Absent bowel movements/ } \\
\text { Inability to pass flatus }\end{array}$ & & \\
\hline constipation & 42 & 84 \\
\hline SIGNS & 24 & 48 \\
\hline Rigidity & 12 & 24 \\
\hline Mass & 10 & 20 \\
\hline Visible peristalsis & 32 & 64 \\
\hline Tenderness & 39 & 78 \\
\hline Tachycardia & 05 & 10 \\
\hline Previous surgical Scar & \multicolumn{2}{|l}{} \\
\hline
\end{tabular}

In the present study $\mathrm{n}=27(54 \%)$ of patients were due to obstructed/strangulated hernia $n=6(12 \%)$ was with adhesions in $\mathrm{n}=6(12 \%)$, Intussusception was found in $n=5(10 \%)$ of patients Malignancy and volvulus was found in $n=3(6 \%)$ of the cases of the study shown in table 3. Hernioplasty was 
performed in $\mathrm{n}=20(40 \%)$ of the patients and hernioplasty with adhesiolysis in $n=7(14 \%)$ of the patients. Untwisting the volvulus was done in $\mathrm{n}=3(6 \%)$, Adhesiolysis was performed in $\mathrm{n}=6(12 \%)$ of patients. Resection and anastomosis were performed in $\mathrm{n}=10(20 \%)$ of the patients. Ileotransverse anastomosis was done in $n=4(8 \%)$ of the patients.

Table 3: The etiology of acute intestinal obstruction in the study

\begin{tabular}{|l|c|c|}
\hline Etiology & $\begin{array}{c}\text { Number of } \\
\text { cases }\end{array}$ & percentage \\
\hline $\begin{array}{l}\text { Obstructed/strangulated } \\
\text { hernia }\end{array}$ & 27 & 54 \\
\hline Adhesions & 06 & 12 \\
\hline Malignancy & 03 & 6 \\
\hline Intestinal tuberculosis & 00 & 00 \\
\hline Volvulus & 03 & 6 \\
\hline Intussusceptions & 05 & 10 \\
\hline Others & 06 & 12 \\
\hline Total & 50 & 100 \\
\hline
\end{tabular}

The post-operative complications were recorded in the study. The most common complication was wound infection in $n=2(4 \%)$ of cases. This was managed adequately with wound debridement and antibiotics. The other complication in $n=1(2 \%)$ was due to septicemia, anastomotic leakage, and hematoma. All the complications were managed adequately without any adverse outcomes

Table 4: Postoperative complications recorded in the study

\begin{tabular}{|l|c|c|}
\hline Post Operative complication & $\begin{array}{c}\text { Number of } \\
\text { Cases }\end{array}$ & Percentage \\
\hline Wound infections & 02 & 04 \\
\hline Wound dehiscence & 00 & 00 \\
\hline Fecal fistula & 00 & 00 \\
\hline Septicemia & 01 & 02 \\
\hline Anastomotic leakage & 01 & 02 \\
\hline Others & 01 & 02 \\
\hline Total & 05 & 10 \\
\hline
\end{tabular}

\section{Discussion}

Acute intestinal obstruction is a surgical emergency and requires quick and correct diagnosis as well as an immediate and effective surgical intervention ${ }^{[7,8]}$. It is also one of the major causes of morbidity and financial expenditure in hospitals across the world and contributes to the number of admissions in emergency surgical units $^{[8]}$. The major cause of acute intestinal obstructions in the current study was due to obstructed/strangulated hernia in $\mathrm{n}=24(54 \%)$, Adhesions was the second common cause with $\mathrm{n}=6(12 \%)$ of patients. Adhesions were the common cause of acute intestinal obstruction in the western population and Middle East countries $^{[9,10]}$. The hernia is the cause of the obstructions in populations who are socioeconomically poor and have lesser access to the quality health care system. S Adhikari et al $;^{[11]}$ in Eastern India found obstructed hernia as the common cause for intestinal obstructions agreeing with the findings of the present study. Some studies have shown that the most common causes in the following decreasing order of appearance in patients include post-operative adhesions, obstructed/strangulated hernia, carcinoma, Intussusception, Volvulus, tuberculosis and mesenteric ischemia ${ }^{[9,12,13]}$. The male to female ratio in the present study was 5:2. S Ullah et al; ${ }^{[14]}$ in their study showed the M: F ratio of 1.6:1. NA Qureshi et al; ${ }^{[15]}$ found a male to female ratio of 1.9:1. In all the studies there is a general agreement that more numbers of the male are involved as compared to females. The age incidence of cases in the study was a maximum of $24 \%$ between $61-70$ years followed by $20 \%$ in $41-$ 50 years age group. The mean age in the current study was 47 years. JS Khan et al; ${ }^{[16]}$ have found the mean age at 33 years and S Adhakari et al; ${ }^{[11]}$ found the mean age of cases of acute intestinal obstruction at 44 years. The most important sign of presentation in the patients is abdominal pain in $100 \%$ of patients followed by constipation in $84 \%$, distension in $68 \%$ of patients. L Sharma et $\mathrm{al}^{[17]}$ in a similar study found abdominal distension in $88 \%$, constipation in $87 \%$ and abdominal pain in $81 \%$ of patients. In the present study majority of patients reported to the hospital in 24-48 hours of the onset of symptoms and were treated successfully. Late presentation is the major 
cause of higher complications, longer hospital stay, and high mortality rates. In the present study, surgical management was done by Hernioplasty in $n=20(40 \%)$ of the patients and hernioplasty with adhesiolysis in $\mathrm{n}=7(14 \%)$ of the patients. Untwisting the volvulus was done in $\mathrm{n}=3(6 \%)$, Adhesiolysis was performed in $n=6(12 \%)$ of patients. Resection and anastomosis were performed in $n=8(16 \%)$ of the patients one case colon cancer was managed by Hartman's procedure and one case by transverse loop colostomy ${ }^{[18,19]}$ Ileotransverse anastomosis was done in $n=4(8 \%)$ of the patients.

\section{Conclusion}

Acute intestinal obstruction is a life-threatening surgical emergency and requires prompt diagnosis and effective therapy. The most common etiological factor for acute intestinal obstruction in our study was hernia followed by adhesions. Best outcomes are for patients with early diagnosis and skillful management within a reasonable time frame. Poor prognosis is generally related to older patients and late presentation to the hospital. The most commonly encountered postoperative complications were wound infections they can be decreased by using prophylactic antibiotics.

\section{Conflict of interest: None}

Source of support: Nil

Ethical permission: Obtained

\section{References}

1. Markogiannakis $\mathrm{H}, \mathrm{Messaris} \mathrm{E}$, Dardamanis D, Pararas N et al; Acute mechanical bowel obstruction: clinical presentation, etiology, management and outcome. World J Gastroenterol 2007; 13:432-37.

2. Shelton BK. Intestinal obstruction. AACN Clin Issues 1999;10:478-91.

3. Maglinte DD, Heitkamp DE, Howard TJ, Kelvin FM, Lappas JC. Current concepts in imaging of small bowel obstruction. Radiol Clin North Am 2003;41:263-83.

4. Springer JE, Bailey JG, Davis PJB, Johnson PM. Management and outcomes of small bowel obstruction in older adult patients: a prospective cohort study. Canadian Journal of Surgery. 2014;57(6): 379-84.

5. Zbar RI, Crede WB, McKhann CF, Jekel JF. The postoperative incidence of small bowel obstruction following standard, open appendectomy and cholecystectomy: a six-year retrospective cohort study at Yale-New Haven Hospital. Conn Med. 1993Mar;57(3):123-27.

6. Thampi D, Tukka VN, Bhalki N, Sreekantha, Remya, SSA. A clinical study of surgical management of acute intestinal obstruction. Int J Res Health Sci. 2014 Jan31; 2(1):299-08.

7. Lyon C, Clark DC. Diagnosis of acute abdominal pain in older patients. Am Fam Physician. 2006; 74:1537.

8. Dang C, Aguilera P, Dang A, et al. Acute abdominal pain. Four classifications can guide assessment and management. Geriatrics 2002; 57:30-2.

9. Chen XZ, Wei T, Jiang K, Yang K, Zhang $\mathrm{B}$, Chen ZX, et al. Etiological factors and mortality of acute intestinal obstruction: A review of 705 cases. Zhong $\mathrm{Xi}$ Yi Jie He Xue Bao 2008;6:1010.

10. Mohamed AY, Al-Ghaithi A, Langevin JM, Nassar AH. Causes and management of intestinal obstruction in a Saudi Arabian hospital. J R Coll Surg Edinb 1997;42:2123.

11. Adhikari S, Hossein MZ, Das A, Mitra N, Ray U. Etiology and outcome of acute intestinal obstruction: A review of 367 patients in Eastern India. Saudi J Gastroenterol 2010;16:285-87.

12. Ojo EO, Ihezue $\mathrm{CH}$, Sule AZ, Ismaila OB, Dauda AM, Adejumo AA. Etiology, clinical pattern and outcome of adult 
intestinal obstruction in JOS, North

Central Nigeria. Af J Med Sci. 2014;43:29.

13. Schmutz GR, Benko A, Fournier L, Peron JM, Morel E, Chiche L. Small bowel obstruction: role and contribution of sonography. Eur Radiol. 1997;7(7):105458.

14. Ullah S, Khan M, Mumtaz N, Naseer A. Intestinal obstruction: A spectrum of causes. J Postgrad Med Inst 2009;23:18692.

15. Qureshi NA, Bhat SK, Sodhi BS. Spectrum of Etiology of Intestinal Obstruction - A Hospital-based Study. Int J Sci Stud 2017;5(5):85-89.

16. Khan JS, Alam J, Hassan H, Iqbal M. Pattern of intestinal obstruction-a hospitalbased study. Pak Armed Forces Med J 2007;57:295-99.

17. Sharma L, H Srivastava, D Kumar P, S Kothari, R Dhawan, P M. Purohit. Acute intestinal obstruction: small intestine vs. large intestine: an analysis Int Surg J. 2018 Jan;5(1):162-167.

18. Chang CC, Chen YY, Chen YF, Lin CN, Yen HH, Lou HY. Acute intussusception in Asians; clinical presentation, diagnosis, and treatment. J Gastroenterol Hepatol 1997 Nov;22(11):1767-71.

19. Agaoglu N (Mustafa NA), Yucel Y, Turkytlmaz S. Surgical treatment of the sigmoid volvulus. Acta Chir Belg 2005;105:365-68. 